\title{
Carnitine and Dehydroepiandrosterone Sulfate Induce Protein Synthesis in Porcine Primary Osteoblast-Like Cells
}

\author{
K. M. Chiu, ${ }^{1}$ E. T. Keller, ${ }^{2}$ T. D. Crenshaw, ${ }^{3}$ S. Gravenstein ${ }^{4}$ \\ ${ }^{1}$ Program in Osteoporosis and Bone Biology, University of California, San Francisco, San Francisco, California 94115, USA \\ ${ }^{2}$ The Unit for Laboratory Animal Medicine, the Department of Pathology, and the Geriatric Center, University of Michigan, \\ Ann Arbor, Michigan 48109, USA \\ ${ }^{3}$ Department of Animal Sciences, University of Wisconsin, Madison, Wisconsin 53706, USA \\ ${ }^{4}$ The Glennan Center for Geriatrics and Gerontology, Suite 201 Hofheimer Hall, 825 Fairfax Avenue, Eastern Virginia Medical School, \\ Norfolk, Virginia 23507-1912, USA
}

Received: 5 December 1997 / Accepted: 1 October 1998

\begin{abstract}
Age-related bone loss eventually leads to osteopenia in men and women. The etiology of age-related bone loss is currently unknown; however, decreased osteoblast activity contributes to this phenomenon. In turn, osteoblast proliferation and function is dependent on energy production, thus the loss of energy production that occurs with age may account for the deficient osteoblast activity. Carnitine and dehydroepiandrosterone-sulfate (DHEAS), both of which decline with age, promote energy production through fatty acid metabolism. Thus, we hypothesized that carnitine and DHEAS would increase osteoblast activity in vitro. Accordingly, we measured the effect of carnitine and DHEAS on palmitic acid oxidation as a measure of energy production, and alkaline phosphatase (ALP) activity and collagen type I (COL) as indices of osteoblast function in primary porcine osteoblast-like cell cultures. Carnitine $\left(10^{-3}\right.$ and $\left.10^{-1} \mathrm{M}\right)$ but not DHEAS $\left(10^{-9}, 10^{-8}\right.$, and $\left.10^{-7} \mathrm{M}\right)$ increased carnitine levels within the cells. Carnitine alone and in combination with DHEAS increased palmitic acid oxidation. Both carnitine and DHEAS alone and in an additive fashion increased ALP activity and COL levels. These results demonstrate that in osteoblast-like cells in vitro, energy production can be increased by carnitine and osteoblast protein production can be increased by both carnitine and DHEAS. These data suggest that carnitine and DHEAS supplementation in the elderly may stimulate osteoblast activity and decrease age-related bone loss.
\end{abstract}

Key words: Osteoblast - Carnitine - Dehydroepiandrosterone sulfate - Alkaline phosphatase - Collagen Type I.

Bone loss is often divided into two broad mechanisms: (1) postmenopausal bone loss, characterized by increased osteoclast activity, and (2) age-related bone loss, characterized by decreased osteoblast activity. Osteoblast activity is dependent on energy production. Thus, it is plausible that the loss of energy production, which accompanies age, may account for decreased osteoblast activity. Most cells use both glucose and fatty acid oxidation pathways for ATP synthesis, although some cell types show a substrate pref-

Correspondence to: S. Gravenstein erence. For instance, some studies have suggested that glucose is the major fuel substrate for bone $[1,2]$. However, more recent work indicates that cell populations enriched with osteoblast-like cells generate $40-80 \%$ of the energy demands through fatty acid oxidation [3]. Osteoblasts are responsible for bone formation and it follows that they maintain a high rate of ATP utilization to support the requisite protein synthesis. Cells with a high rate of protein synthesis generate ATP from fatty acid oxidation, the most efficient metabolic process for energy production [4-6]. Thus, modulation of fatty acid oxidation may regulate the amount of energy available for protein synthesis in osteoblasts.

A number of factors are required for fatty acid oxidation. For example, carnitine is the requisite carrier for the transport of long-chain fatty acids across the inner mitochondrial membrane into the mitochondrial matrix [7]. In muscle, carnitine concentration decreases with advancing age [8-10]. This decline may contribute to diminution of mitochondrial function associated with age. We have observed that the ratio of esterified to free carnitine in the peripheral blood increases with age [11], suggesting a declining ability for fatty acid transport. Accordingly, this decline may contribute to reduced energy availability with age, culminating in cardiomyopathy, hepatic encephalopathy, or skeletal muscle weakness [12]. This loss of energy availability could also compromise osteoblast activity and bone production in an age-related manner.

Another factor indirectly related to fatty acid oxidation is dehydroepiandrosterone (DHEA), an intermediate in the pathway for the synthesis of testosterone, estrone, and estradiol [13]. DHEA and its sulfated derivative, DHEAS, are interconvertible and DHEAS is the major source of circulating DHEA [14]. The physiologic roles of DHEA and DHEAS have not been conclusively defined. However, DHEA and DHEAS increase lipid metabolism and mitochondrial respiration $[15,16]$. This may be accomplished through DHEA's ability to increase the synthesis and activity of carnitine acyltransferases, enzymes which catalyze the reversible transfer of the fatty acid moiety from fatty acyl CoA to fatty acyl-carnitine $[17,18]$. Additionally, our laboratory has demonstrated that DHEAS administration increases hepatic and cardiac carnitine levels and carnitine acetyl transferase activities in young adult oophorectomized rats [19]. Taken together, these observations stimulate ques- 
tions about potential roles that DHEA, through promotion of energy metabolism, might play on osteoblast activity.

As osteoblasts have high-energy requirements and both carnitine and DHEAS play an important role in energy metabolism we propose that both carnitine and DHEAS promote fatty acid oxidation and energy metabolism in osteoblasts. Accordingly, the aim of this study was to investigate the effects of carnitine and DHEAS on primary cultures of porcine bone marrow stromal cells (BMSC).

\section{Materials and Methods}

\section{Cell Isolation and Culture}

Porcine bone marrow stromal cells were isolated using the methods described by Thomson et al. [20]. Briefly, cultures consisting of bone marrow stromal cells (progenitor osteoblast cells) and trabecular bone cells (mature osteoblast cells) were prepared from distal femurs of young, 3 to 4 -week-old pigs. Soft tissue was removed, the bone was immersed in $70 \%$ ethanol, and then transferred to a flow hood for aseptic collection of bone cells. Bones were sectioned at the metaphysis, and tissue from trabeculae and medullary cavity as transferred into a flask containing Dulbecco's Modified Eagle's Medium (DMEM) (Gibco, Grand Island, NY) plus $10 \%$ fetal bovine serum (FBS) (Biowhittaker, Inc. Walkersville, MD). Cells were grown to confluence, then nonadherent cells were discarded and adherent cells were subcultured to a new flask following treatment with trypsin-EDTA $(0.05 \%$ trypsin, $0.53 \mathrm{mM}$ EDTA-4Na) (Gibco, Grand Island, NY). Medium was completely changed twice weekly and adherent bone marrow stromal cells were passed approximately weekly when cultures became confluent. These cell cultures were heterogeneous and included osteoblast-like cells at various stages of differentiation [20].

\section{Mineralized Bone Nodule Formation}

Cultures were grown with $50 \mu \mathrm{g} / \mathrm{ml}$ ascorbic acid, $10 \mathrm{mM} \beta$-glycerophosphate, and $10^{-8} \mathrm{M}$ dexamethasone for 7-10 days, as previously described by Maniatopoulos et al. [20]. Under these conditions, mineralized bone nodules were identified by staining the cell cultures with Alizarin red S.

\section{Histochemical Staining for Alkaline Phosphatase}

Bone marrow stromal cells were seeded at $2 \times 10^{5}$ cells in a $35 \mathrm{~mm}$ culture dish with $10 \%$ FBS/DMEM, and cultured for 24 hours. The medium was then removed and BMSC were fixed in $10 \%$ neutral buffered formalin. Alkaline phosphatase was stained using ImmunoPure Fast Red TR, (Sigma Chemical Co., St. Louis, MO) the naphthol phosphate AS-MX.

\section{Determination of Cell Number and Viability}

DNA Incorporation. Cells were seeded in 96-well plates (4000 cells/well) in $0.1 \%$ FBS/DMEM for 24 hours to synchronize the cell cycle. DMEM with $10 \%$ FBS and $\left[{ }^{3} \mathrm{H}\right]$ thymidine $(0.2 \mu \mathrm{Ci} / \mathrm{ml})$ (New England Nuclear, Boston, MA) were added and the cultures were incubated for 20 hours at $37^{\circ} \mathrm{C}$. At the end of this 20 -hour incubation period, the medium was removed and cell layers were washed three times with PBS. Cells were then trypsinized for 20 minutes and harvested onto fiberglass filter papers, and the radioactivity was counted with a $\beta$-scintillation counter (1600TR, Parkard, Meriden, CT).

\section{Cell Viability}

Trypan blue exclusion. Cells were plated in $35 \mathrm{~mm}$ culture dishes at an initial density of $2 \times 10^{5}$ cells/dish in $0.1 \% \mathrm{FBS} /$
DMEM. After a 24-hour attachment period, the medium was changed to $10 \%$ FBS/DMEM for another 24-hour incubation at $37^{\circ} \mathrm{C}$. The cells were then released by trypsin, a $0.04 \%(\mathrm{w} / \mathrm{v})$ trypan blue solution in phosphate-buffered saline (PBS) was added, and the number of viable cells (nonstained) were counted using a hemacytometer.

MTT [3, (4, 5-Dimethylthiazol-2-yl) 2, 5-diphenyl-tetrazolium Bromide] Assay. MTT assay is an indirect measurement of cell growth. Cells were cultured in 96-well plates (4000 cells/well) in $0.1 \%$ FBS/DMEM for 24 hours. DMEM supplemented with $10 \%$ FBS was added and the cultures were incubated for another 24 hours at $37^{\circ} \mathrm{C}$. MTT [3, (4, 5-dimethylthiazol-2-yl) 2, 5-diphenyltetrazolium bromide] (Sigma) was added and after 4 hours of incubation, cells were extracted with an extraction buffer $(\mathrm{N}, \mathrm{N}$ dimethyl formamide/sodium dodecyl sulfate) to lyse the cells and solublize all formazan dye grains [22]. After an overnight incubation, optical densities at $570 \mathrm{~nm}$ were measured by automated ELISA plate reader (Dynatech MR650, Alexandria, VA).

\section{Addition of Treatments}

The cells were cultured in 2\% FBS/DMEM in 96-flat-bottom-well plates (4000 cells/well). After an attachment period of 24 hours, either or both carnitine and DHEAS were added at the indicated concentrations and the cells were cultured for an additional 72 hours. L-carnitine (Austin Chemical Co., Chicago, IL) was dissolved in $2 \% \mathrm{FBS} / \mathrm{DMEM}$ to provide final concentrations in culture media of $10^{-1} \mathrm{M}, 10^{-2} \mathrm{M}$, and $10^{-3} \mathrm{M}$. DHEAS (Sigma) was dissolved in $100 \%$ ethanol to provide a $10^{-3} \mathrm{M}$ stock solution, and then diluted into $10^{-7} \mathrm{M}, 10^{-8} \mathrm{M}$, and $10^{-9} \mathrm{M}$ final concentrations with $2 \%$ FBS/DMEM. Carnitine and DHEAS were added to the cell culture separately or in the following combinations: $10^{-1}$ $\mathrm{M}$ carnitine plus $10^{-7} \mathrm{M}$ DHEAS, $10^{-1} \mathrm{M}$ carnitine plus $10^{-8} \mathrm{M}$ DHEAS, or $10^{-1} \mathrm{M}$ carnitine plus $10^{-9} \mathrm{M}$ DHEAS. For the control, only $2 \%$ FBS/DMEM was added to the cell culture.

\section{Alkaline Phosphatase Assay (ALP)}

At the end of the 72 hour incubation period, the medium was removed. The cells were then rinsed with PBS and lysed by three freeze-thaw cycles in lysate buffer $(0.1 \%$ Triton $\mathrm{X}-100,10 \mathrm{mM}$ Tris, and $0.5 \mathrm{mM} \mathrm{MgCl}_{2}$ ). ALP activity was measured at $37^{\circ} \mathrm{C}$ following the addition of $2 \mathrm{mg} / \mathrm{ml}$ of $p$-nitrophenylphosphate (Sigma) substrate [19]. The plates were read at $410 \mathrm{~nm}$ using a plate reader (Dynatech MR650). Bovine intestinal mucosal ALP (Sigma) was used to construct a standard curve. One unit of enzyme activity equals one $\mu$ mole product formed per minute.

\section{Collagen Type I Assay (COL)}

The COL concentration was measured by ELISA [23] and modified from the immunocytochemistry method from Thomson et al. [20]. At the end of the 72-hour incubation period, the medium was removed. The cells were then rinsed with PBS and fixed with $4 \%$ formalin for 10 minutes at room temperature. The cells were then rinsed with PBS-T twice. Goat anti-type I collagen antibody (0.4 $\mu \mathrm{g} / 100 \mu \mathrm{l} /$ well) (Southern Biotechnology Associates, Inc., Birmingham, AL) was added and incubated for 2 hours at room temperature, then rinsed with PBS-T three times. Anti-goat IgG conjugated with ALP $(0.135 \mu \mathrm{g} / 150 \mu \mathrm{l} /$ well) (Sigma) was used as a second antibody and incubated for another 2 hours at room temperature. The cells were then rinsed with PBS-T three times. $p$-Nitrophenylphosphate $(1 \mathrm{mg} / \mathrm{ml})$ was added and the absorbance at $410 \mathrm{~nm}$ was recorded as described above. Interference from endogenous cellular ALP activity, determined by using the ALPconjugated secondary antibody alone, was minimal. 


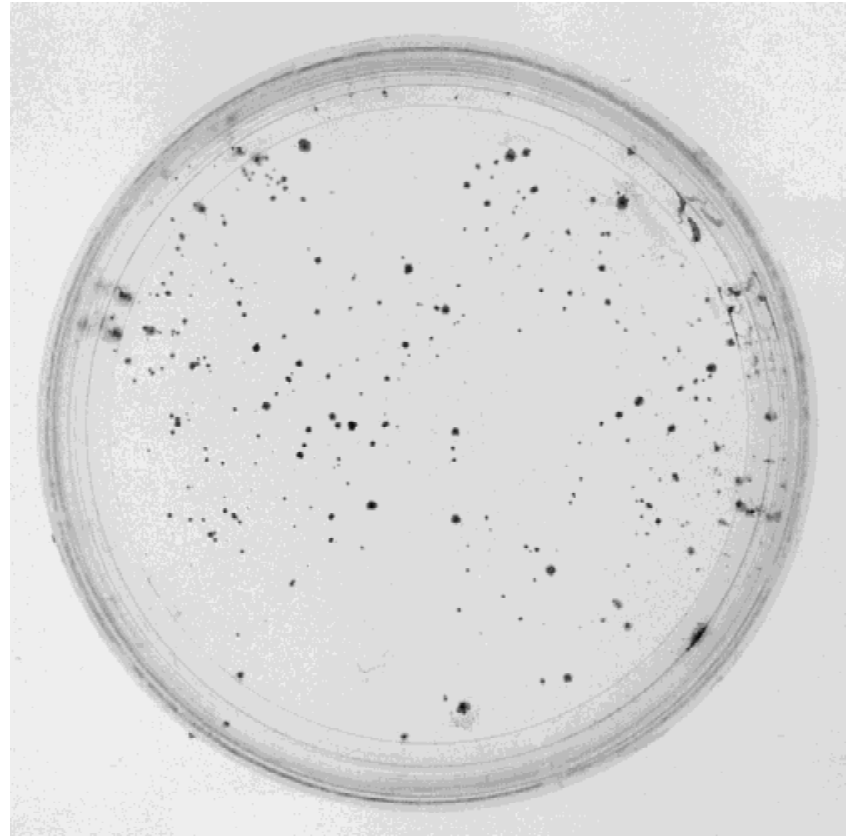

Fig. 1. Cells harvested from the porcine distal femur are capable of mineralization. Cells were harvested from the distal femoral metaphyseal trabeculae of pigs. They were then grown with 50 $\mu \mathrm{g} / \mathrm{ml}$ ascorbic acid, $10 \mathrm{mM} \beta$-glycerophosphate and $10^{-8} \mathrm{M}$ dexamethasone in $10 \% \mathrm{FBS} / \mathrm{BGJ}_{\mathrm{b}}$ medium for 7-10 days at which time they were then stained with Alzarin red.

layers were rapidly rinsed three times with cold PBS. The cells were lysed by three freeze-thaw cycles in lysate buffer $(0.1 \%$ Triton X-100, $10 \mathrm{mM}$ Tris and $0.5 \mathrm{mM} \mathrm{MgCl}_{2}$ ). The cell lysates were stored at $-80^{\circ} \mathrm{C}$ until analysis. Carnitine was measured in triplicate by quantitative radioenzymatic assay slightly modified from that reported by Parvin and Pande [24]. Free carnitine was measured in untreated samples whereas total carnitine was determined after alkaline hydrolysis. Results were expressed as nmol/ mg noncollagen protein (NCP). NCP was determined by Biorad micro protein assay kit with globulin as a standard (\#500-0001 protein assay kit, Bio-Rad Laboratories, Inc., Hercules, CA) [25].

\section{Fatty Acid Oxidation}

The cells were seeded in $35 \mathrm{~mm}$ culture dishes $\left(2 \times 10^{5} / \mathrm{dish}\right)$ in $2 \%$ FBS/DMEM. After an attachment period of 24 hours, carnitine and DHEAS were added separately or in combination to the cultures. $\left[9,10^{-3} \mathrm{H}\right]$-Palmitic acid $(0.5 \mu \mathrm{Ci} / \mathrm{ml}$, specific activity 56.5 $\mathrm{Ci} / \mathrm{mmol}$ ) (Du Pont-New England Nuclear, Wilmington, DE) and nonradioactive palmitate were prebound to fatty acid free albumin (Sigma) and added to provide a final concentration of $0.4 \mathrm{mM}$ palmitate. After 24 -hours of incubation at $37^{\circ} \mathrm{C}$, the medium and cell lysate were used to measure the tritiated water production as an estimate of exogenous fatty acid oxidation. Tritiated water, formed during $\beta$-oxidation of labeled $\left[9,10^{-3} \mathrm{H}\right]$-palmitic acid, served as a tracer for exogenous fatty acid transport and oxidation. The medium or cell lysate was added to $5 \mathrm{ml}$ of Dole-Meinertz extraction solution [26], vortexed, and then allowed to stand for 15 minutes. After adding $2 \mathrm{ml}$ of water and $3 \mathrm{ml}$ of heptane and vortexing, it was allowed to stand for 15 minutes and then the upper organic phase was removed. The lower aqueous phase, which contained ${ }^{3} \mathrm{H}_{2} \mathrm{O}$ and acid-soluble products of fatty acid metabolism, was then counted on a Parkad Tricarb liquid scintillation counter.
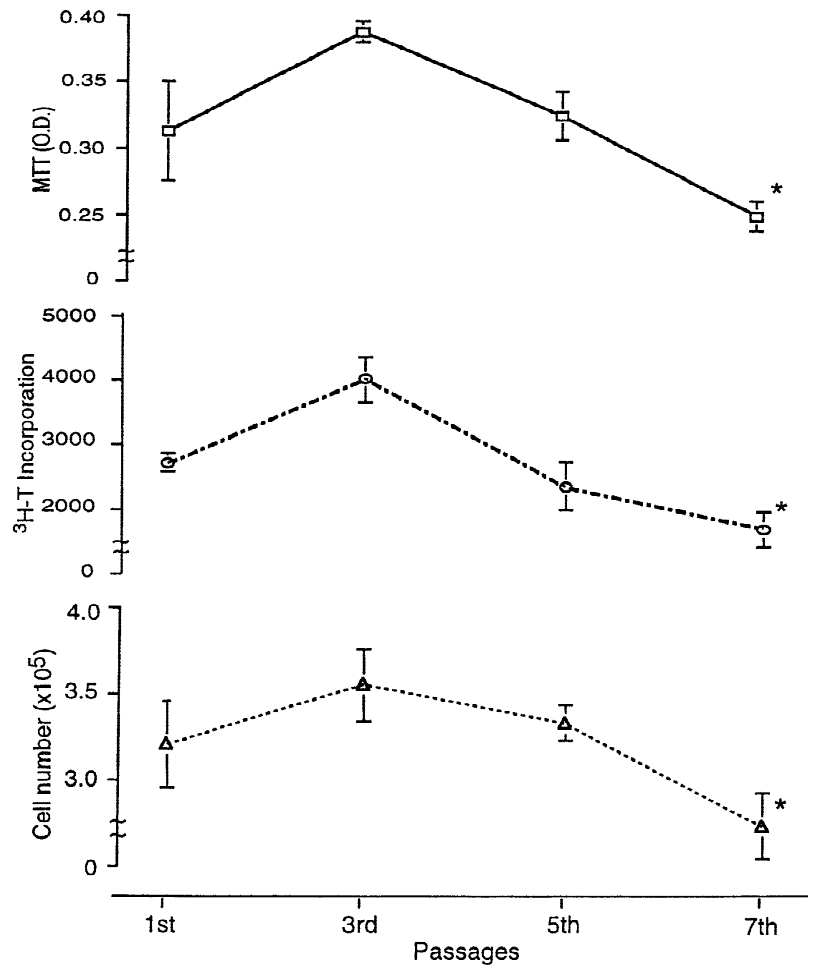

Fig. 2. Osteoblast-like cell proliferation decreases with increasing number of passages in culture. Cells were maintained in $10 \%$ FBS/DMEM for 1st, 3rd, 5th, and 7th passages. At each passage, cells were treated as described in Materials and Methods. Each value (mean \pm SEM) represents the average of five trials. $* P \leqslant$ 0.002 compared with the 3rd passage by ANOVA.

\section{Statistical Analysis}

For total and free carnitine concentrations and palmitate oxidation, analysis of variance (ANOVA) was used to compare the means of control and treated groups. Data were expressed as the mean \pm standard error of the mean (SEM). For ALP activities and COL levels, ANOVA on rank-transformed data for randomized complete block design was performed to compare the different groups [26]. Data were expressed as median (first quartile-third quartile). Data analyses were conducted using SAS (SAS Institute Inc., Cary, NC) and Statview version 4.02 Software (Abacus Concepts, Berkeley, CA). Significant difference was set at $P \leqslant 0.05$.

\section{Results}

\section{Model System}

This model system has been previously well described [20]. However, mineralizing capability and the ALP activity were measured to confirm the presence of osteoblast-like cells in our cultures. Mineralized bone nodules were formed in the primary cultures indicating that osteoblast-like cells were present (Fig. 1). Immunochemical ALP-positive staining also supported the presence of osteoblast-like cells in the cultures (data not shown). The three assays $\left({ }^{3} \mathrm{H}\right.$ thymidine, trypan blue exclusion, and MTT) used to assess DNA incorporation and viability of the bone marrow stromal cells 
Table 1. Effect of carnitine and DHEAS on total and free carnitine concentrations in pig osteoblast-like cells

\begin{tabular}{|c|c|c|c|c|c|c|c|c|c|c|}
\hline \multirow[b]{2}{*}{ Parameter } & \multirow[b]{2}{*}{ Control } & \multicolumn{3}{|c|}{ L-carnitine (M) } & \multicolumn{3}{|c|}{ DHEAS (M) } & \multicolumn{3}{|c|}{ L-carnitine $\left(10^{-1} \mathrm{M}\right)+$ DHEAS $(\mathrm{M})$} \\
\hline & & $10^{-3}$ & $10^{-2}$ & $10^{-1}$ & $10^{-9}$ & $10^{-8}$ & $10^{-7}$ & $10^{-9}$ & $10^{-8}$ & $10^{-7}$ \\
\hline $\begin{array}{l}\text { Total } \\
\text { carnitine }\end{array}$ & $2.1 \pm 0.4^{\mathrm{b}}$ & $6.4 \pm 1.4^{*}$ & $43 \pm 10 * *$ & $225 \pm 71 * *$ & $2.1 \pm 0.6$ & $2.0 \pm 0.5$ & $1.9 \pm 0.2$ & $218 \pm 35^{* *}$ & $196 \pm 60 * *$ & $185 \pm 43^{* *}$ \\
\hline $\begin{array}{l}\text { Free } \\
\quad \text { carnitine }\end{array}$ & $1.7 \pm 0.5$ & $4.9 \pm 1.0^{*}$ & $39 \pm 11 * *$ & $211 \pm 75 * *$ & $1.9 \pm 0.5$ & $2.0 \pm 0.6$ & $1.9 \pm 0.3$ & $201 \pm 37 * *$ & $200 \pm 49 * *$ & $184 \pm 51^{* *}$ \\
\hline
\end{tabular}

a nmole/mg noncollagen protein, replicates

b All data are expressed as mean \pm SEM. Each value represents the average of 7 replicates

$* P \leqslant 0.05 ; * * P \leqslant 0.01$

in cultures showed similar responses across the number of passages. The maximal DNA incorporation and cell viability occurred in the third passage $(34 \pm 1.3$ days old) and gradually declined through the seventh passage (Fig. 2). There was a $40-50 \%$ decline in both of these measures from the third passage to the seventh passage $(P=0.002)$.

\section{Cellular Total and Free Carnitine Concentrations}

Total and free intracellular carnitine levels were measured to confirm that in vitro administration of carnitine was effective. The total and free carnitine concentrations in the third passage of BMSC, cultured with $10^{-1} \mathrm{M}$ carnitine alone or in the presence of DHEAS, increased above control cultures approximately 90-100-fold whereas cells from cultures treated with $10^{-2} \mathrm{M}$ or $10^{-3} \mathrm{M}$ carnitine had a 20 -fold or 3-fold increase in cellular carnitine concentrations, respectively (Table 1). DHEAS did not effect the total of free carnitine levels.

\section{Fatty Acid Oxidation}

To determine if carnitine and DHEAS, either alone or in combination, promotes energy production, fatty acid oxidation was measured using palmitate as the substrate. The amount of palmitate oxidized by the cell cultures with $10^{-1}$ M carnitine alone or combined with DHEAS $(P \leqslant 0.01)$, was greater than oxidation by control cultures (Table 2 ). The combination of carnitine and DHEAS was additive. Palmitate oxidation $(P \leqslant 0.088)$ tended to increase in cultures treated with $10^{-2} \mathrm{M}$ carnitine or $10^{-8} \mathrm{M}$ and $10^{-7} \mathrm{M}$ DHEAS.

\section{Osteoblast Proteins}

To determine if carnitine and DHEAS-mediated energy availability was associated with increased osteoblast protein production, we measured ALP and COL accumulation in culture. Both carnitine and DHEAS alone significantly increased ALP activity (Table 3). Compared with the control cultures, ALP activities increased in cultures treated with $10^{-2} \mathrm{M}-10^{-1} \mathrm{M}$ carnitine $(P<0.01)$. DHEAS $\left(10^{-7} \mathrm{M}-10^{-9}\right.$ M) also stimulated ALP activities $(P \leqslant 0.05)$, but the response was not dose dependent. Treatments with both carnitine and DHEAS were additive in increasing ALP activities when compared with the control cultures $(P \leqslant 0.01)$.

Over a twofold increase in COL concentration was ob- served in cultures treated with $10^{-1} \mathrm{M}$ carnitine and a significant increase in cultures treated with $10^{-2} \mathrm{M}$ carnitine compared with the control $(P \leqslant 0.01)$ (Table 3$)$. Compared with controls, the combination of $10^{-1} \mathrm{M}$ carnitine and DHEAS $\left(10^{-7} \mathrm{M}-10^{-9} \mathrm{M}\right)$ also increased the COL levels $(P$ $\leqslant 0.01)$. DHEAS $\left(10^{-7}-10^{-9} \mathrm{M}\right)$ did not increase COL levels significantly. Carnitine and DHEAS treatment did not increase viable cell counts compared with control groups (data not shown). Thus, the observed differences in ALP and COL were not due to increased cell proliferation between the various treatments, but more likely to increased expression of ALP and COL per a cell.

\section{Discussion}

In this study, carnitine promoted energy production through increased fatty acid oxidation in cell cultures containing osteoblast-like cells. Furthermore, ALP activity and COL levels, proteins indicative of osteoblastic activity, increased concomitant with the increased energy availability in carnitine-treated cells.

Lower mitochondrial carnitine concentrations are associated with diminished activity of enzymes involved in fatty acid oxidation $[9,28,29]$. In addition, the rate of fatty acid oxidation and the removal of potentially toxic intracellular acyl CoA esters are dependent upon carnitine [28, 30, 31]. We observed that carnitine treatment elevated the total carnitine concentration that was associated with greater fatty acid oxidation. These findings support the fact that carnitine supplementation increases osteoblast-like cell activity by increasing transfer of fatty acids into mitochondria for oxidation.

With advancing age, carnitine and acetyl carnitine levels are markedly reduced in certain tissues, including muscle [8-10]. The potential for carnitine deficiency/insufficiency appears to increase with age, and is more prevalent among women [11]. If there is a severe deficiency, cardiomyopathy, hepatic encephalopathy, or skeletal muscle weakness could ensue. This metabolic defect might also affect bone formation since osteoblast activity and bone mineral density (BMD) decline with advancing age [32, 33]. In elderly people, if osteoblasts are carnitine deficient, less energy may be available at the cellular level and thus limit osteoblast function. Cellular energy deficits caused by a decline in mitochondrial function can impair normal cellular activities and affect the cell's ability to adapt to various physiological stresses [34].

In our study, high concentrations of carnitine are added to stimulate palmitate oxidation, ALP activities, and COL levels in the osteoblast-like cell cultures. Physiologic serum 
total carnitine levels in men and women are $55 \pm 12$ and 47 $\pm 11 \mu$ moles/liter, respectively [36]. Tissue total carnitine levels (skeletal muscle, heart, and liver) are $14 \pm 3,9 \pm 2$, and $10 \pm 3 \mathrm{nmol} / \mathrm{mg}$ noncollagen protein, respectively [36]. However, high doses of carnitine therapy, from 100 up to $600 \mathrm{mg} / \mathrm{kg}$ daily, are required to treat carnitine deficiency $[35,36]$. Our demonstration that high levels of carnitine were required to observe a significant effect on energy metabolism protein production in osteoblasts agrees with these studies. One possible explanation for the requirement of high carnitine levels in our model is that the in vitro environment results in inefficient utilization of carnitine as opposed to the in vivo environment. Further studies are required to explore this issue.

The exact physiologic role that DHEAS plays in bone metabolism is unclear. However, several reports suggest that DHEAS promotes bone density. For example, DHEAS levels were correlated with skeletal maturation [37]. Additionally, DHEAS is positively correlated to BMD and declines with age [38-41]. Finally, exogenous administration of DHEA reduced cancellous bone osteopenia in oophorectomized rats [42]. The mechanism through which DHEAS mediates its effects on bone is currently unknown, but could include direct or indirect modulation of hormonal mechanisms [43]. Our data suggest that DHEAS promotes osteoblast activity which was not due to increased cellular carnitine concentration, increased energy metabolism, or differences in cell viability. Our observation that DHEAS increases liver total and free carnitine concentrations in rats [19] suggests that it may also do so in bone, which would lead to energy production. However, we could not document that DHEAS induced either carnitine levels or fatty acid metabolism in the osteoblast cultures. Thus, our findings suggest that DHEAS promotes protein production in osteoblasts through other mechanisms, such as increasing mitochondrial respiration $[16,44]$, protein synthesis $[18$, 45], and enzyme activities [17, 18, 46, 47].

A limitation of our study is the use of an in vitro model that contains a heterogenous population of cells. However, this well-documented system has been previously used for evaluation of osteoblast-like cells [20]. Furthermore, we confirmed the presence of osteoblast-like cells in the cultures through the identification of mineralized bone nodule formation and ALP staining cells.

In conclusion, carnitine alone and in combination with DHEAS stimulated the metabolic activity of early passage osteoblast-like cells in vitro. Carnitine achieved this through promotion of fatty acid metabolism culminating in increased osteoblast protein production. Furthermore, DHEAS increased osteoblast protein production by an undefined mechanism. These findings suggest that carnitine and DHEAS may promote osteoblast function. Thus, because carnitine and DHEAS levels decline with advancing age, carnitine and DHEAS supplementation for promotion of osteoblast activity and bone formation in elderly persons may be worth investigating.

Acknowledgment. The authors would like to thank Ms. Mary Schmidt (Metabolic Analysis Lab, Inc., Madison, WI) for her technical advice on the carnitine assay. We also thank Dr. Dennis Paulson (Department of Physiology, Midwestern University, Downers Grove, IL) for his advice on fatty acid oxidation and Mr. Tom Havighurst (Department of Biostatistics, University of Wisconsin-Madison) for helping with the statistical analysis. This work was supported in part by NIH Grants RO1-AG09632 (SG), K08-AG00548 (SG), R01-AG015904 (EK), Glenn/American Fed- 
Table 3. Effect of carnitine and DHEAS on osteoblast proteins in pig osteoblast-like cells

\begin{tabular}{|c|c|c|c|c|c|c|c|c|c|c|}
\hline \multirow[b]{2}{*}{ Parameter } & \multirow[b]{2}{*}{ Control } & \multicolumn{3}{|c|}{ L-carnitine (M) } & \multicolumn{3}{|c|}{ DHEAS (M) } & \multicolumn{3}{|c|}{ L-carnitine $\left(10^{-1} \mathrm{M}\right)+$ DHEAS $(\mathrm{M})$} \\
\hline & & $10^{-3}$ & $10^{-2}$ & $10^{-1}$ & $10^{-9}$ & $10^{-8}$ & $10^{-7}$ & $10^{-9}$ & $10^{-8}$ & $10^{-7}$ \\
\hline $\mathrm{ALP}^{\mathrm{a}}$ & $\begin{array}{l}5.9 \\
(3.6-7.3)\end{array}$ & $\begin{array}{l}6.4 \\
(4.5-8.3)\end{array}$ & $\begin{array}{l}7.1 * * \\
(6.5-8.3)\end{array}$ & $\begin{array}{l}7.7 * * \\
(6.0-10.8)\end{array}$ & $\begin{array}{l}6.8 * * \\
(4.4-9.0)\end{array}$ & $\begin{array}{l}6.6^{*} \\
(4.0-8.8)\end{array}$ & $\begin{array}{l}6.7 * \\
(4.9-8.4)\end{array}$ & $\begin{array}{l}8.8 * * \\
(8.4-11.1)\end{array}$ & $\begin{array}{l}8.7 * * \\
(8.6-11.0)\end{array}$ & $\begin{array}{l}8.2 * * \\
(6.8-11.8)\end{array}$ \\
\hline $\mathrm{COL}^{\mathrm{b}}$ & $\begin{array}{l}8.0 \\
(5.0-9.5)\end{array}$ & $\begin{array}{l}8.0 \\
(4.0-10.0)\end{array}$ & $\begin{array}{l}11.5 * * \\
(8.5-15.0)\end{array}$ & $\begin{array}{l}18.5 * * \\
(12.5-22.0)\end{array}$ & $\begin{array}{l}9.5 \\
(7.5-12.0)\end{array}$ & $\begin{array}{l}9.5 \\
(6.5-11.0)\end{array}$ & $\begin{array}{l}10.0 \\
(7.5-11.0)\end{array}$ & $\begin{array}{l}20.5^{* *} \\
(18.0-24.0)\end{array}$ & $\begin{array}{l}21.0 * * \\
(18.0-28.5)\end{array}$ & $\begin{array}{l}21.5^{* *} \\
(17.5-25.0)\end{array}$ \\
\hline
\end{tabular}

alkaline phosphatase $\left(\times 10^{5} \mathrm{U} / \mu \mathrm{g}\right.$ protein $)$

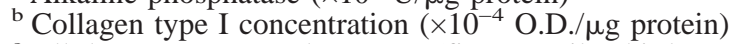

${ }^{c}$ All data are expressed as mean (first quartile-third quartile). Each value represents the average of 5 or 4 replicates for ALP and COL, respectively.

$* P \leqslant 0.05 ; * * P \leqslant 0.01$

eration For Aging Research Scholarship, 1995 (SG and KMC) and the College of Agriculture and Life Sciences 133-Q893 (TC).

\section{References}

1. Schmid C, Steiner T, Froesch ER (1982) Insulin-like growth factor I supports differentiation of cultured osteoblast-like cells FEBS Lett 148:31-34

2. Schmid C, Steiner T, Froesch ER (1983) Insulin-like growth factors stimulate synthesis of nucleic acids and glycogen in cultured calvaria cells Calcif Tissue Int 35:578-585

3. Adamek G, Felix R, Guenther HL, Fleisch H (1987) Fatty acid oxidation in bone tissue and bone cells in culture. Biochem $\mathrm{J}$ 248:129-137

4. Newsholme P, Gordon S, Newsholme EA (1987) Rates of utilization and fates of glucose, glutamate, pyruvate, fatty acids and ketone bodies by mouse macrophages. Biochem J 242:631-636

5. Eigenbrodt E, Glossman H (1980) Glycolysis-one of the keys to cancers? Trends Pharmacol Sci 1:240-247

6. Dyson RD (1975) Mitochondrial and chloroplasts. In: Dyson RD (eds) Cell biology: a molecular approach. Allyn and Bacon, Boston, London, Sydney, p 184

7. Borum PR (1983) Carnitine. Ann Rev Nutr 3:233-259

8. Costell M, Grisolia S (1992) Effect of carnitine feeding on the levels of heart and skeletal muscle carnitine of elderly mice. FEBS 315:43-46

9. Costell M, O'Connor JE, Grisolia S (1989) Age-dependent decrease of carnitine content in muscle of mice and humans. Biochem Biophys Res Commun 161:1135-1143

10. Maccari F, Arseni A, Chiodi P, Ramacii MT, Angelucci L (1990) Levels of carnitines in brain and other tissues of rats of different ages: effect of acetyl-L-carnitine administration. Exp Gerontol 25:127-134

11. Chiu KM, Schmidt MJ, Havighurst TC, Shug AL, Daynes RA, Keller ET, Gravenstein S (1999) Correlation of serum Lcarnitine and dehydro-epiandrosterone sulphate levels with age and sex in healthy adults. Age and Aging

12. Scholte HR, Rodrigus Pereira R, de Jonge PC, Luyt-Houwen Inez EM, Verduin MHM, Ross JD (1990) Primary carnitine deficiency. J Clin Chem Clin Biochem 28:351-357

13. VandeWiele RL, MacDonald PC, Gurpide E, Lieberman S (1963) Studies on the secretion and interconversion of androgens. Recent Progr Horm Res 19:275-310

14. Bird CE, Murphy J, Boroomand K, Finnis W, Dressel D, Clark AF (1978) Dehydroepiandrosterone: kinetics of metabolism in normal men and women. J Clin Endocrinol Metab $47: 818-822$

15. Berdanier C, Parente J, Mcintosh M (1993) Is dehydroepiandrosterone an antiobesity agent? FASEB 7:414-419

16. Mohan PH, Cleary MP (1991) Short-term effects of dehydroepi-androsterone treatment in rats on mitochondrial respiration. J Nutri 121:240-250

17. Yamada J, Sakuma M, Suga T (1992) Induction of peroxisomal b-oxidation enzymes by dehydroepiandrosterone and its sulfate in primary cultures of rat hepatocytes. Biochim Biophys Acta 1160:231-236
18. Brady LJ, Ramsay RR, Brady PS (1991) Regulation of carnitine acyltransferase synthesis in lean and obese Zucker rats by dehydroepiandrosterone and clofibrate. J Nutr 121:525-531

19. Chiu KM, Schmidt MJ, Shug AL, Binkley N, Gravenstein S (1997) Effect of dehydroepiandrosterone sulfate on carnitine acetyl transferase activity and L-carnitine levels in oophorectomized rats. Biochim Biophys Acta 1344:210-209

20. Thomson BM, Bennett J, Dean V, Triffitt J, Meikle MC, Loveridge N (1993) Preliminary characterization of porcine bone marrow stromal cells: skeletogenic potential, colonyforming activity, and response to dexamethasone, transforming growth factor $\mathrm{b}$, and basic fibroblast growth factor. J Bone Miner Res 8:1173-1183

21. Maniatopoulos C, Sodek J, Melcher AH (1988) Bone formation in vitro by stromal cells obtained from bone marrow of young rats. Cell Tissue Res 254:317-330

22. Hansen MB, Nielsen SE, Berg K (1989) Re-examination and further development of a precise and rapid dye method for measuring cell growth/cell kill. J Immunol Methods 119:203210

23. Crowther JR (1995) Indirect ELISA. In: Crowther J.R. (ed) ELISA theory and practice. Humana Press Inc, New Jersey, pp 131-137

24. Parvin R, Pande SV (1977) Microdetermination of L-carnitine and carnitine acetyl transferase activity. Anal Biochem 79: 190-201

25. Bradford M (1976) A rapid and sensitive method for the quantitation of microgram quantities of protein utilizing the principle of protein-dye binding. Anal Biochem 72:248-254

26. Paulson DJ, Mathews R, Bowman J, Zhao J (1992) Metabolic effects of treadmill exercise training on the diabetic heart. J Appl Physiol 73:265-271

27. Iman RL, Hora SC, Conover WJ (1984) Comparison of asymptotically distribution-free procedures for the analysis of complete blocks. J Am Statistical Assoc 79:674-685

28. Hansford R, Castro F (1982) Age-linked changes in the activity of enzymes of the tricarboxylate cycle and lipid oxidation, and of carnitine content, in muscles of the rats. Mech Ageing Dev 19:191-201

29. Hansford RG (1978) Lipid oxidation by heart mitochondria from young adult and senescent rats. Biochem J 170:285-295

30. Rebouche CJ (1992) Carnitine function and requirements during the life cycle. FASEB J 6:3379-3386

31. Bremer J (1990) The role of carnitine in intracellular metabolism. J Clin Chem Clin Biochem 28:297-301

32. Egrise D, Martin D, Vienne A, Neve P, Schoutens A (1992) The number of fibroblastic colonies formed from bone marrow is decreased and the in vitro proliferation rate of trabecular bone cells increased in aged rats. Bone 13:355-361

33. Favus MJ (1993) Bone density reference data. In: Favus MJ (ed) Primer on the metabolic bone diseases and disorders of mineral metabolism. Raven Press, New York, NY, pp 426430

34. Shigenaga MK, Hagen TM, Ames BN (1994) Oxidative dam- 
age and mitochondrial decay in aging. Proc Natl Acad Sci USA 91:10771-10778

35. Angelini C, Lucke S, Cantarutti F (1976) Carnitine deficiency of skeletal muscle: report of a treated case. Neurology 26: 622-637

36. Winter SC, Zorn EM (1990) Carnitine deficiency. Lancet 335: 981-982

37. Wierman ME, Beardsworth OE, Crawford JP, Creglir JR, Mansfield JM, Bode Hans H, Boepple PA, Kusher DC, Crowley WF (1986) Adrenarche and skeletal maturation during luteinizing hormone releasing analogue suppression of gonadarche. J Clin Invest 77:121-124

38. Nordin BEC, Robertson A, Seamark RF, Bridges A, Philcox JC, Need AG, Horowitz M, Morris HA, Deam S (1985) The relation between calcium absorption, serum dehydroepiandrosterone, and vertebral mineral density in postmenopausal women. J Clin Endocrinol Metab 60:651-657

39. Deutsch S, Benjamin F, Seltzer V, Tafreshi M, Kocheril G, Frank A (1987) The correlation of serum estrogens and androgens with bone density in the late postmenopause. Int $\mathrm{J}$ Gynaecol Obstet 25:217-222

40. Barrett-Connor E, Kritz-Silverstein D, Edelstein SL (1993) A prospective study of dehydroepiandrosterone sulfate (DHEAS) and bone mineral density in older men and women. Am J Epidemiol 137:201-206

41. Wild RA, Buchanan JR, Myers C, Demers LM (1987) De- clining adrenal androgens: an association with bone loss in aging women. Proc Soc Exp Bio Med 186:355-360

42. Turner RT, Lifrak ET, Beckner M, Wakley GK, Hannon KS, Parker LN (1990) Dehydroepiandrosterone reduces cancellous bone osteopenia in ovariectomized rats. Am J Physiol 258:E673-E677

43. Schweikert HU, Rulf W, Milderle N, Schafer HE, Kech E, Kruck F (1980) Testosterone metabolism in human bone. Acta Endocrinol 95:258-264

44. Bellei M, Battelli D, Fornieri C, Giuseppe M, Muscatello U, Lardy H, Bobyleva V (1992) Changes in liver structure and function after short-term and long-term treatment of rats with dehydroepiandrosterone. J Nutr 122:967-976

45. Prough RA, Webb SJ, Wu HQ, Lapenson DP, Waxman DJ (1994) Induction of microsomal and peroxisomal enzymes by dehydroepiandrosterone and its reduced metabolite in rats. Cancer Res 54:2878-2886

46. Sakuma M, Yamada J, Suga T (1992) Comparison of the inducing effect of dehydroepiandrosterone on hepatic peroxisome proliferation-associated enzymes in several rodent species. Biochem Pharmacol 43:1269-1273

47. Frenkel RA, Slaughter CA, Orth K, Moomaw CR, Hicks SH, Snyder JM, Bennett M, Prough RA, Putnam RS, Milewich L (1990) Peroxisome proliferation and induction of peroxisomal enzymes in mouse and rat liver by dehydroepiandrosterone feeding. J Steroid Biochem 35:333-342 